\title{
Gender Differences in Interactions with Avatars of Diverse Ethnic Appearances
}

Galina Ya. Menshikova*, Olga. A. Tikhomandritskaya, Olga A. Saveleva, Tatyana V. Popova

Lomonosov Moscow State University, Moscow, Russia

${ }^{*}$ Corresponding Author. E-mail: gmenshikova@gmail.com

Background. Gender differences exist in almost every aspect of our lives. Individuals have an array of different social expectations with regard to behaviors, communication, appearance, attitudes, and social roles, but these expectations tend to be based on whether the individual is male or female. Currently, many social studies have been done with the help of virtual reality technologies. They have been effectively applied to the study of many social phenomena such as nonverbal communication, social skills training, social anxiety rehabilitation, etc. Recently considerable attention has been paid to issue of gender differences during social interaction with the virtual partners, avatars. However, the question of gender differences during interactions with avatars of diverse ethnic appearances has seldom been studied.

Objective. The goal of this study was to investigate the gender peculiarities of interaction with avatars of different ethnic appearances. We used the CAVE virtual reality system to study gender differences in interpersonal distances which were maintained with avatars.

Design. We designed four three-dimensional virtual scenes with avatars of four different ethnic appearances. They were avatars of Slavic, Asian, North Caucasian, and African appearance. All the avatars were male. The participants (who all identified as Russians) were immersed in virtual environments with the help of the CAVE virtual reality system. Their task was to approach the avatar, present herself/himself in any way they wanted, and give instructions for the work. During the task the interpersonal distances between the participants and the avatars were measured. After leaving the CAVE, the participants were asked to fill out a questionnaire assessing the Presence effect.

Results. The results showed gender differences in how much interpersonal distance was maintained: women preferred to keep shorter interpersonal distances with their virtual partners than men did. Moreover, the results showed the impact of ethnic appearance on interpersonal distances. Women approached the avatars of their own ethnic group more closely and kept further away from the avatars of other ethnic groups. Unlike the women, the men stayed the same distance away from the avatars of different ethnic groups. Both gender groups kept equally far away from the avatar of African appearance. Gender differences were also revealed in the participants' estimates of the Presence effect. 
Conclusion. We developed a comprehensive method for analyzing the gender differences in interaction with the avatars, including both subjective (the sense of Presence, semantic differential technique) and objective (assessment of interpersonal distance) characteristics. This method allowed us to assess gender variables during the social interaction using both behavioral and psychological responses. The same method can be applied successfully to the study of gender differences regarding other social phenomena.

Keywords: gender differences, interethnic interaction, interpersonal distance, avatar, Presence effect, CAVE virtual reality technology

\section{Introduction}

The social perception which occurs in interpersonal interaction is among the most important aspects of communication (Andreeva, 1990). A large number of social, personal, and situational factors have an effect on communicative behavior. One of these factors is gender, which is determined by the behaviors and attitudes that a society considers proper for its males and females (Klecina, 2003; Henslin, Nelson, 1997). Considerable attention has recently been paid to the question of gender differences within social interaction (Andreeva, 2013; Reeder, 2009; Eagly, Wood, 2013). Many studies have shown that women and men communicate very differently in many key aspects (Eagly, 1983; Block, 1976).

In communication, each person takes a certain gender role according to specific gender stereotypes, including behavioral features of men and women which are widespread in his or her society. The content and origins of gender stereotypes differ in different cultures, and vary in intensity and forms across countries. Many modern studies have shown that communication style (nonverbal behavior, linguistic strategies, aggression, leadership, self-esteem, etc.) differs between sexes in their particular cultures (Hofstede, McCrae, 2004; Xiufang Xia, 2013; Zell et al., 2015).

Researchers studying gender pay attention to nonverbal behavioral cues, such as gestures, facial expressions, postures, and appearance. One of the several subcategories in the study of nonverbal communication is proxemics, i.e. how humans use space to interact with others in everyday life. The basic concept of proxemics is interpersonal distance (Hall, 1966), which can transmit a lot of information about the communication process: the degree of sympathy and trust between the partners in the dialogue, the social status of the communicating persons, the duration of their acquaintance, respect, etc. (Henley, LaFrance, 1984).

The spatial behavior of a person takes place in the context of individual psychological, environmental, and socio-cultural factors, which include ethnicity and gender. In particular, the organization of interpersonal space varies according to the partner's gender. Many researchers have found that the space organized by women was more compact than the space organized by men (Kreidlin, 2005). This behavior was considered a manifestation of female communication style: women are more open, friendlier, and more focused on establishing comfortable conditions for cooperation. Studies of spatial behavior have traditionally used methods such as observation, survey, and experiment.

Currently, digital technologies, particularly virtual reality (VR) systems, are in wide use in the studies of social processes (Zinchenko et al., 2015; Fox et al., 2009; Blascovich et al., 2002). Nonverbal behavior is one of the psychological phenom- 
ena explored with the help of VR technologies, which were developed in order to study interaction with virtual partners. It has been shown that the participants may perceive a virtual partner in two different ways: as an agent (a virtual partner controlled by a computer program), or an avatar (a partner representing another character). In the latter case the participant's behavior was revealed to be very similar to the behavior that he or she exhibits with human beings (Lucas et al., 2014; Bailenson et al., 2008). This similarity was particularly evident in the proxemics: participants preferred not to violate their personal space when communicating with avatars (Bailenson et al., 2003; Menshikova et al., 2018). These and many other studies have shown that interaction with virtual partners can contribute to social behavior training, and then the skills acquired in a virtual environment extrapolated into real life (Menshikova et al., 2017).

Much of the research applying VR systems to studying social phenomena has considered gender behavior in the process of "user-avatar" interaction. For example, in a 2013 study by Preda and Jovanova, the influence of the gender of both the participant and the avatar on the efficiency of communication was investigated. Virtual partners (male and female), who differed in the degree of their behavioral realism, were designed. The avatars were constructed highly realistically: Their lip movements could match the phonemes spoken; they could blink their eyes, and turn their heads to follow the participant's glance to keep eye-contact. The results showed that the participants perceived avatars of their own gender as more truthful (Nowak, Rauh, 2008), and that a male agent was perceived as more convincing compared to a female avatar.

The avatar's gender has also been demonstrated to be a factor (Petrakou, 2010; Pals et al., 2014). Researchers investigating the interpersonal distance maintained with the avatars have found that the most important factors affecting whether an avatar would be admitted into the user's interpersonal space were:

- the gender of both the participant and the avatar: if they coincided, the interpersonal distance decreased;

- the direction of the avatar's gaze: in the case of direct eye-contact, the interpersonal distance increased.

The influence of the gender and personality characteristics of participants on their emotional preferences when communicating with avatars was also been demonstrated (Diemer et al., 2015). Diemer et al. showed that women who were introverts preferred to communicate with avatars which were similar to themselves in appearance, whereas women who were extroverts chose to communicate with avatars of different appearance, e.g. having brighter clothes or different hairstyles, or even belonging to other ethnic or racial groups.

From the very beginning of VR application to social studies, the question of whether the participant believed the virtual world as real has been actively discussed (Riva, 1999). The perceptual experience, which enables users to believe that they are "being there" in the virtual world, is important for assessing the impact of the virtual environment. The effectiveness of virtual environments has often been linked to the sense of Presence. Presence is defined as the subjective experience of being in the virtual environment, even when the user is physically situated in the real environment. The Presence effect is considered an indicator of immersion in 
the virtual environment and is measured using the Presence questionnaire (Witmer, Singer, 1998).

The application of VR systems has proven effective in the study of gender differences of the "user-avatar" interaction. However, some aspects of this issue have not yet been studied sufficiently. In particular, the interaction between two important factors of communication-the gender and ethnic appearance of the avatarsremains unclear. To measure the role of a participant's gender in interactions with avatars of different ethnic appearances, we evaluated the behavioral (interpersonal distances) and psychological (Presence effect) responses.

\section{Goal}

The goal of our study was to investigate gender differences during the interactions with avatars of different ethnic appearances. The following research hypotheses were tested:

- There will be gender differences in the interpersonal distances maintained with avatars: women will keep shorter interpersonal distances from avatars in comparison with men.

- There will be gender differences in the interpersonal distances depending upon the ethnic appearance of the avatars: women will come closer to avatars of their own ethnic group.

- There will be gender differences in the intensity of Presence effect.

- The interpersonal distance will correlate with the intensity of the Presence effect: the higher the degree of Presence, the longer interpersonal distance will be chosen by the participants when interacting with the avatars.

\section{Design}

Participants. The sample consisted of 41 participants (22 females, 19 males, age 18 to 26 years). All participants had normal or corrected-to-normal vision and had no vestibular disorders or brain injuries. All participants declared themselves ethnic Russians. All of them live permanently in Moscow and the Moscow region. The small sample size was due to the complexity of our experimental procedure and the large amounts of data they produce.

Stimulation. Four three-dimensional virtual scenes with avatars were designed. Each virtual scene represented a large room connected to the office where the virtual partner was standing. Four types of avatars of different ethnic appearance were created, including avatars of Slavic, Asian, North Caucasian, and African appearance. All avatars were male. The appearance of the avatars slightly differed in the manifestation of masculine-feminine features: the avatar of North Caucasus appearance had more expressed masculine features, the avatar of Slavic appearance showed less pronounced masculine features, and the avatars of Asian and African appearance had moderately expressed features. Figure 1 shows a scene of interaction of a participant with one of the avatars of African appearance.

Equipment. The virtual scenes were presented using CAVE virtual reality system Barco Ispace 4 with a screen resolution of 1280 x1024 and a field of view of 
$180^{\circ}$. Special glasses CrystalEyes 3 allowed the participant to form 3D virtual objects and characters. Participants could move through the virtual environment using a manipulator Flystick2. The participant's location was recorded with an $8 \mathrm{~Hz}$ update frequency. Unity $3 D$ Professional was used for the software development.

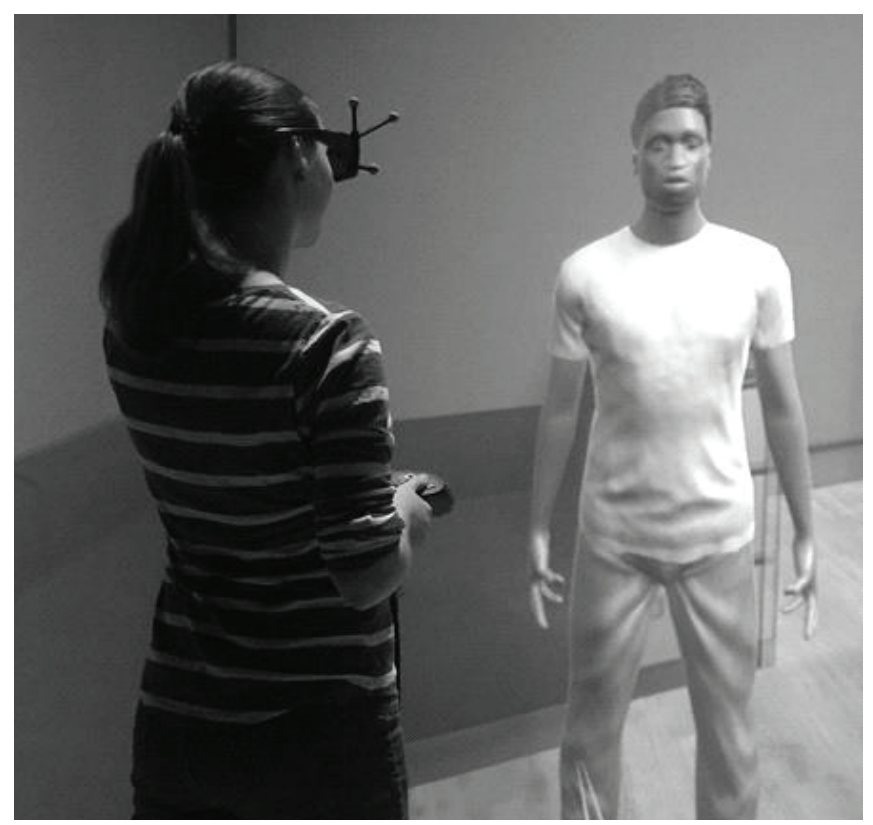

Figure 1. A participant communicating with an avatar of African appearance.

Procedure. The participants first had to be trained to navigate through the virtual space using a Flystick. When they reported that they were ready, the main experiment started. Each participant got into the starting position in the center of the virtual room, and was asked to go into the office room where the avatar was standing. According to the scenario, the participant played the role of an employer who had to hire a designer, an architect, and an engineer (avatar roles) to build country houses. The avatars represented workers who came for an interview. The participant's task was to approach the avatar, introduce herself/himself in any way they wanted, and give instructions for the house construction. There was no time limit. Then the participant interacted with the three avatars of other ethnic appearance in the same way. The order of interaction with the avatars of different ethnic appearance was quasi-random. The spatial coordinates of the participant's movement in the virtual environment were recorded. On average, the interaction process with all avatars lasted for 2-3 hours.

After all the tasks in the virtual environment were completed, each participant was asked to fill out a questionnaire to assess the strength of the Presence effect. The standard questionnaire of B. Whitmer and M. Singer (Witmer, Singer, 1998) was modified in accordance with the objectives of this experiment. The modified version contained 17 questions, which assessed the general impression of the virtual scenes, and the avatar's appearance and behavior. Four questions specifically addressed the realism of the virtual scenes (№ 10,11, 14, 16); seven questions concerned the emotional impression of "being there" (№ 1, 4, 6, 7, 8, 9, 17); two ques- 
tions were about the appearance of avatars (№ 12, 13); and four questions were about any discomforts of nausea and disorientation arising in the virtual space (№ $2,3,5,15$ ). The participants rated the questions on a scale of 1 to 5 , where 1 corresponded to the minimum, and 5 to the maximum of the sense of being there, in the virtual environment.

Statistical processing. The data were processed with the use of SPSS Statistics 22 software package. The interpersonal distances that participants maintained with the virtual humans were analyzed. The analysis encompassed only the particular zone within which the participant could have an "eye-to-eye" contact with the avatar, not the entire trajectory of motion. This zone was chosen to reduce the variability of interpersonal distance values due to the compensation effect. This effect showed that participants establish a longer distance from the avatars when they are in the "eye-to-eye" zone, and a shorter distance once they leave this zone (Bailenson et al., 2003). For the virtual scenes the boundaries of this zone were determined as values of the visual angle in the range of $\pm 30^{\circ}$ relative to the axis direction of the participant's and the avatar's reciprocal gaze. Within this zone the mean values of interpersonal distance were calculated. The values of the Presence effect were calculated as the average ratings of female and male samples for each ethnic version of the avatar, and for each question separately.

\section{Results}

Two types of data were analyzed separately for the female and male samples:

- the interpersonal distance that participants maintained from the avatars of different ethnic appearance;

- the perceived intensity of the Presence effect and its correlation with the interpersonal distances.

Interpersonal distance maintained by participants with avatars of different ethnic appearance. Based on the data, the average interpersonal distances chosen by the participants during their interaction with avatars of different ethnic groups were calculated separately for the female and male samples. The results are given in Table 1, which shows the average values of distances (in meters) when the participants were facing avatars of African, Asian, Slavic, and North Caucasian appearance. Standard deviations are given in parentheses.

Table 1

The average interpersonal distance maintained with avatars of different ethnic appearances by the male and female participants

\begin{tabular}{llccc}
\hline & $\begin{array}{c}\text { Avatars of Slavic } \\
\text { appearance }\end{array}$ & $\begin{array}{c}\text { Avatars of North } \\
\text { Caucasian } \\
\text { appearance }\end{array}$ & $\begin{array}{c}\text { Avatars of Asian } \\
\text { appearance }\end{array}$ & $\begin{array}{c}\text { Avatars of African } \\
\text { appearance }\end{array}$ \\
\hline Males & $2.21(0.56)$ & $2.22(0.69)$ & $2.21(0.67)$ & $2.35(0.57)$ \\
Females & $2.10(0.59)$ & $2.09(0.67)$ & $2.13(0.56)$ & $2.22(0.64)$ \\
\hline
\end{tabular}




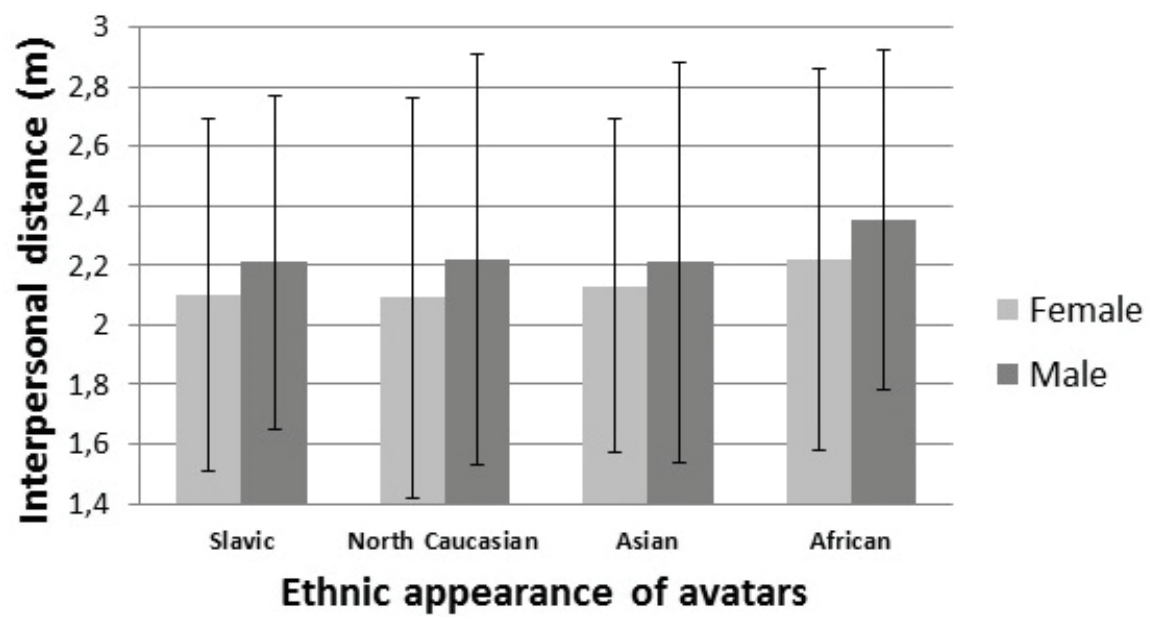

Figure 2. Interpersonal distance (in $\mathrm{m}$ ) maintained by male (black bars) and female (grey bars) participants when interacting with the avatars of different ethnic appearance

The $\mathrm{x}$-axis identifies the four types of ethnic appearance of the avatars. The $y$ axis shows the average interpersonal distance in meters. As seen from the Figure 2, women preferred to maintain shorter interpersonal distance with the avatars than men, regardless of the ethnic appearance of the avatars. The gender differences between the mean interpersonal distances were calculated in pairwise comparison of the male and female samples. A trend of differences between male and female participants interacting with avatars of any ethnic group was observed: with avatars of Slavic appearance $(\mathrm{t}(44)=3.57, \mathrm{p}<0.08)$; avatars of North Caucasian appearance $(\mathrm{t}(44)=3.87, \mathrm{p}<0.05)$; avatars of Asian appearance $(\mathrm{t}(44)=4.15, \mathrm{p}<0.04)$; and avatars of African appearance $(\mathrm{t}(44)=4.07, \mathrm{p}<0.07)$. Thus, the data partially confirmed our hypothesis about gender differences: women were more likely to maintain shorter interpersonal distances during interaction with the avatars than did the men.

These results agree with those of previous studies that revealed the same female behavior: women approached their human communication partner more closely than men did (Evans, Howard, 1973; Gifford, 1982). A similar style of behavior was observed when communicating with the virtual partners. (Bailenson et al., 2003; Bailenson et al., 2008). So, the same social rules are applied in the interactions with both real and virtual partners. The reason for this behavior may be a desire to establish a more emotional relationship with a partner, even if this partner is a virtual character (Labunskaya, 1988; Preda, Jovanova, 2013).

The results also revealed a trend of gender differences in maintaining distances from avatars of different ethnic groups. Women most closely approached the avatars of their own ethnic group; a little less the avatars of North Caucasian appearance $(\mathrm{t}(44)=3.65, \mathrm{p}<0.09)$; and then kept significantly further away from avatars of the Asian ethnic group $(\mathrm{t}(44)=2.44, \mathrm{p}<0.05)$. The longest distance was maintained from the avatars of African appearance $(t(44)=3.57, \mathrm{p}<0.04)$.

Men adhered to a completely different type of behavior. They maintained approximately the same distance from the avatars of Slavic, North Caucasian, and Asian ethnic appearances: The differences between the mean interpersonal dis- 
tances with pairwise comparison of all groups were insignificant. The only exception was avatars of African appearance from whom male participants preferred to maintain a significantly longer distance $(\mathrm{t}(44)=2.37, \mathrm{p}<0.05)$.

We explain this behavior in the following way: our participants, being residents of Moscow and the Moscow region, rarely communicate with representatives of this ethnic group, which in turn may lead to some emotional tension manifested in the increased interpersonal distance. The studies of gender differences in proxemics reveal that men and women behave the same way in relation to strangers (Sukhova, 2002). Thus, these results again show the general strategies of interaction with the real and virtual partners.

\section{The perceived intensity of the Presence effect.}

The average ratings of the Presence effect were calculated for female/male participants separately for each question on the questionnaire. The average scores for each question are shown in Fig. 3. The numbers of the questions are on the $\mathrm{x}$-axis, and the $y$-axis represents the intensity of the Presence effect scored from 1 (minimal intensity) to 5 (maximum intensity). The black bars in Fig. 3 show the average values for the males, and the gray bars those for the females

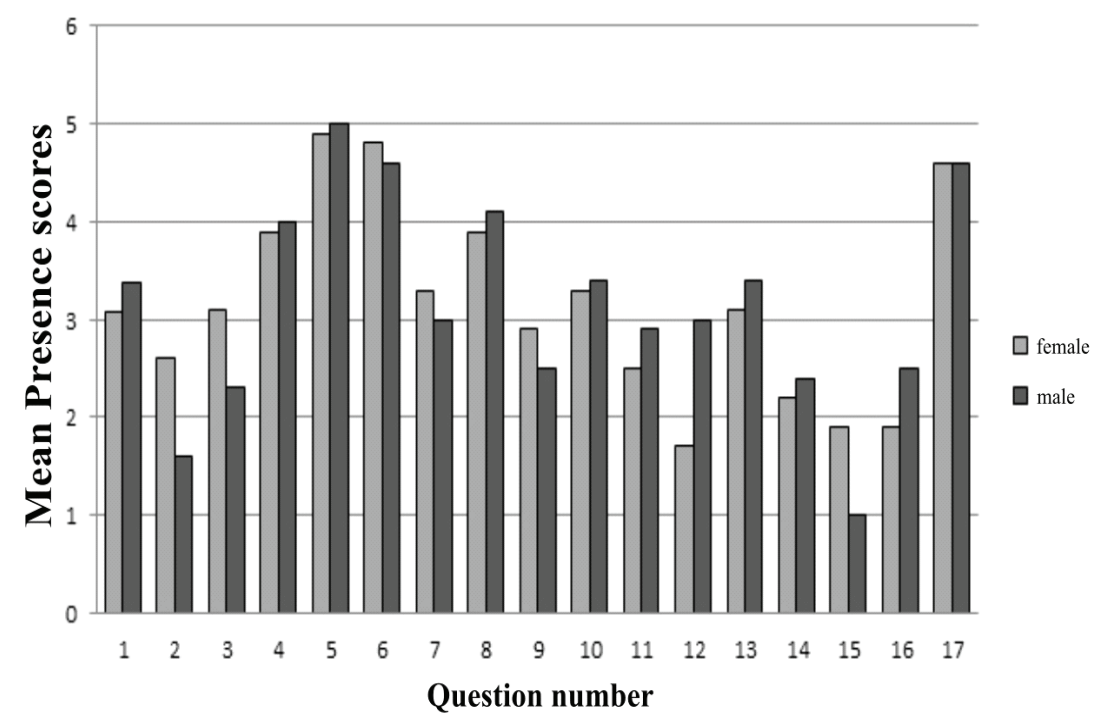

Figure 3. Mean Presence scores versus the question number

for the female (grey bars) and male (black bars) participants

for each question of the questionnaire. In general, the estimates of the Presence effect for the virtual environments and avatars were above average, varying from a minimum value of 1.5 points up to a maximum of 5 points. The analysis of the mean ratings showed that the Presence effect differed insignificantly in the male and female samples: many questions were rated almost equally by men and women.

However, significant differences were found for some questions. According to the responses to questions 2 (I lost orientation in space) and 15 (I felt queasy), men experienced this feeling to a much lesser extent than women; as to question 12 (it seemed to me that the avatar could actually exist), men more often believed in the 
realism of their virtual partners. This result may be explained by the participants' different experiences in using VR systems. Preliminary interviews with our participants showed that men and women differed in their degree of experience interacting with virtual environments. Fifty percent of males had some experience of being in a virtual environment (HMD, CAVE, SUIT, VR), while among females the level of experience was much lower (about 21\%). Thus, as the results show, men are much less likely to lose their orientation in a virtual environment than women, and they are also more likely to perceive avatars as real people. This result coheres with the studies of Maccoby and Jacklin (1974), who revealed the greater ability of men to orient themselves to their environment. This ability also could manifest itself in a virtual environment.

We also calculated the sample correlation coefficient between the values of the mean interpersonal distances and Presence scores, averaged over all 17 questions. The results showed a high negative correlation $(\mathrm{r}=0.57 ; \mathrm{p}=0.01)$, indicating a more pronounced compensation effect if the participant's Presence score was higher. In other words, the more realistic the virtual environment was perceived to be, the larger distances participants kept from the avatars, whatever their ethnic appearance.

In general, the interaction with avatars in a virtual environment was not difficult for our participants; they used the same models of non-verbal behavior as in real communication.

\section{Conclusion}

We developed a comprehensive method for estimating gender differences during interactions with avatars of diverse ethnic appearances, including both subjective (the sense of Presence) and objective (assessment of interpersonal distances) measurements.

Variation by gender was evident in the participants' maintenance of interpersonal distances from the avatars: women were more likely to keep shorter distances away from virtual partners than men.

This trend of gender differences in maintaining interpersonal distance also varied according to the ethnic appearance of the avatars. Women came closer to the avatars of their own ethnic group and kept further away from avatars of other ethnic groups. Unlike women, men adhered to the same distance from the avatars of different ethnic groups. Both kept equally far from the avatar of African appearance.

The Presence effect was almost the same for both gender groups, except that men are less likely to lose orientation in a virtual environment than women, and are more likely to perceive avatars as real people.

The interpersonal distance correlated with the intensity of the Presence effect: the higher the degree of Presence, the longer interpersonal distance was maintained by the participants when interacting with the avatars.

In summary, we have shown that nonverbal behavior of men and women during interaction with avatars in a virtual environment did not differ significantly from their behavior in communication with real people. The usefulness of our method for assessing gender differences is that it gives us the ability to explore 
participants' nonverbal behaviors when interacting with avatars of different ethnic appearances.

\section{Acknowledgements}

This research was supported by Russian Science Foundation, the Grant № 15-1800109, and with the use of equipment purchased with the funds of the "Program of Development of the Lomonosov Moscow State University".

\section{References}

Andreeva, G.M. (1990). Social psychology. Moscow: Progress.

Andreeva, G.M. (2013). Sotsial'naya psikhologiya v prostranstve sovremennoi nauki i kul'tury [Social psychology in space of modern science and culture]. Psikhologicheskie Issledovaniya [Psychological Studies]. 30(6). 2-11. Retrived from http://psystudy.ru/index.php/ num/2013v6n30/861-andreeva30.html

Bailenson, J.N., Blascovich, J., Beall, A.C., \& Loomis, J.M. (2003). Interpersonal distance in immersive virtual environments. Personality and Social Psychology Bulletin. 29(7). 819-833. https://doi.org/10.1177/0146167203029007002

Bailenson, J.N., Yee, N., Blascovich, J., \& Guadagno, R.E. (2008). Transformed social interaction in mediated interpersonal communication. In E. Konijn, S. Utz, M. Tanis, \& S. Barnes (Eds.), Mediated interpersonal communication (pp. 77-99). New York, NY: Routledge.

Blascovich, J., Loomis, J., Beall, A.C., Swinth, K. R., Hoyt, C.L., \& Bailenson, J.N. (2002). Immersive virtual environment technology as a methodological tool for social psychology. Psychological Inquiry, 13(2), 103-124. https://doi.org/10.1207/S15327965PLI1302_01

Block, J.H. (1976). Issues, problems, and pitfalls in assessing sex differences: A critical review of the psychology of sex differences. Merrill-Palmer Quarterly, 22, 193-203.

Diemer, J., Pauli, P., \& Mühlberger, A. (2015). Virtual Reality in Psychotherapy. In J.D. Wright (Eds.), International Encyclopedia of the Social \& Behavioral Sciences (2nd ed., pp. 138-146). Oxford: Elsevier.

Eagly, A.H. (1983). Gender and social influence: A social psychological analysis. American Psychologist, 38, 971-981. https://doi.org/10.1037/0003-066X.38.9.971

Eagly, A.H. \& Wood, W. (2013). The nature-nurture debates: 25 years of challenges in the psychology of gender. Perspectives on Psychological Science, 8, 340-357. https:// doi.org/10.1177/1745691613484767

Evans, G.W., \& Howard, R.B. (1973). Personal space. Psychological Bulletin. 80, 334-344. https://doi.org/10.1037/h0034946

Gifford, R. (1982). Projected interpersonal distance and orientation choices: Personality, sex, and social situation. Social Psychology Quarterly, 45, 145-152. https://doi.org/10.2307/3033647

Fox, J., Arena, D., \& Bailenson, J.N. (2009). Virtual reality: A survival guide for the social scientist. Journal of Media Psychology: Theories, Methods, and Applications, 21(3), 95-113. https://doi.org/10.1027/1864-1105.21.3.95

Hall, E.T. (1966). The Hidden Dimension. New York: Anchor Books.

Henslin, J. M. \& Nelson, A. (1997). Essentials of sociology: A down-to-earth approach. Scarborough, Ont: Allyn and Bacon.

Henley, N.M. \& LaFrance, M. (1984). Gender as Culture: Difference and Dominance in Nonverbal Behavior: Perspectives, Applications, Intercultural Insights. New York: Lewiston. 
Hofstede, G. \& McCrae, R.R.(2004). Culture and personality revisited:Linking traitsanddimensions of culture. Cross-Cultural Research, 38, 52-88. https://doi.org/10.1177/1069397103259443

Klecina, I.S. (2003). Workshop on Gender Psychology. St. Petersburg: Peter.

Kreidlin, T.E. (2005). Men and women in non-verbal communication. Moscow.

Labunskaya, V.A. (1988). Nonverbal behavior (socio-perceptive approach). Rostov-on-Don: Phoenix.

Lucas, G.M., Gratch, J., King, A., \& Morency, L.-P. (2014). It's only a computer: virtual humans increase willingness to disclose. Computers in Human Behavior, 37, 94-100. https://doi. org/10.1016/j.chb.2014.04.043

Maccoby, E.E. \& Jacklin, C.N. (1974). The psychology of sex differences. Stanford, CA: Stanford University Press.

Menshikova, G.Ya., Kovalev, A.I., \& Luniakova, E.G. (2017) Vliyanie rasovoy prinadlejnosti litza na virajennost effekta vzglyada-podskazki: metod aitrekinga [Studying the influence of race on the gaze cueing effect using eye tracking method]. Natsionalnyy psikhologicheskiy zhurnal [National Psychological Journal], 2(26). pp. 46-58.

Menshikova, G.Ya., Saveleva, O.A., \& Zinchenko, Yu.P. (2018). The study of ethnic attitudes during interactions with avatars in virtual environments. Psychology in Russia: State of the Art, 11(1), 20-31.

Menshikova, G.Ya, Zinchenko, Yu.P., Chernorizov, A.M., Tikhomandritskaya, O.A., Shaigerova, L.A., Isaychev, S.A, Kovalev, A.I., Saveleva, O.A., Kraschilschikova, N.O. \& Popova, T.V. (2017). Tekhnologiya virtualnoy i dopolnennoy realnosti v issledovanii fenomena etnokulturnoy identichnosti, mezhetnicheskogo i mezhkulturnogo vzaimodeystviya [The technology of virtual and augmented reality in the study of the phenomenon of ethnocultural identity, interethnic and intercultural interaction]. In Rossiyskaya identichnost. Psikhologicheskoe blagopoluchie. Sotsialnaya stabilnost [Russian identity. Psychological well-being. Social stability] (pp. 260-330), Moscow, Lomonosov Moscow State University (in Russ.).

Nowak, K.L. \& Rauh, C. (2008). Examining the perception process of avatar anthropomorphism, credibility and androgyny in static and chat context. Computers in Human Behavior, 24(4), 1473-1493. https://doi.org/10.1016/j.chb.2007.05.005

Pals, R., Steg, L., Dontje, J., Siero, F., \& Van der Zee, K. (2014). Physical features, coherence and positive outcomes of person-environment interactions: A virtual reality study. Journal of Environmental Psychology, 40, 108-116. https://doi.org/10.1016/j.jenvp.2014.05.004

Petrakou, A. (2010). Interacting through avatars: Virtual worlds as a context for online education. Computers \& Education, 54(4), 1020-1027. https://doi.org/10.1016/j.compedu.2009.10.007

Preda, M. \& Jovanova, B. (2013). Avatar interoperability and control in virtual Worlds. Signal Processing: Image Communication, 28(2), 168-180.

Reeder, H.M. (2009). A critical look at gender difference in communication research. Communication Studies, 47(4), 318-330. https://doi.org/10.1080/10510979609368486

Riva, G. (1999). Virtual reality as communication tool: a socio-cognitive analysis. Presence Teleoperators \& Virtual Environments, 8, 462-468. https://doi.org/10.1162/105474699566341

Sukhova, N. (2002). Gendernye osobennosti neverbalnogo povedeniya [Gender features of nonverbal behavior]. In Gendernye issledovaniya i gendernoe obrazovanie v vysshey shkole [Gender Studies and Gender Education in Higher Education]. Ivanovo: IvGU. Retrived from file:///Users/anastasia-sidneva/Downloads/2_Gender_Ivanovo_02\%20(1).pdf

Witmer, B.G. \& Singer, M.J. (1998). Measuring presence in virtual environments: A presence questionnaire. Presence: Teleoperators and Virtual Environment, 7, 225-240. https://doi. org/10.1162/105474698565686 
Xiufang Xia (2013). Gender Differences in Using Language. Theory and Practice in Language Studies, 3(8), 1485-1489. https://doi.org/10.4304/tpls.3.8.1485-1489

Zell, E., Krizan, Z., \& Teeter, S.R. (2015). Evaluating gender similarities and differences using metasynthesis. American Psychologist, 70(1), 10-20. https://doi.org/10.1037/a0038208

Zinchenko, Yu. P., Kovalev, A.I., Menshikova, G.Ya., \& Shaigerova, L.A. (2015). Postnonclassical methodology and application of virtual reality technologies in social research. Psychology in Russia: State of the Art, 8(4), 60-71. https://doi.org/10.11621/pir.2015.0405

Original manuscript received April 12, 2018 Revised manuscript accepted November 16, 2018

First published online December 30, 2018 